\title{
On the acquisition of a gastroscope
}

\author{
HAROLD C EDWARDS
}

In an issue of the Lancet in the earlier part of 1933 there appeared an editorial entitled "The Flexible Gastroscope." It had been invented in 1932 by Dr Schindler in cooperation with the Berlin optical manufacturer Georg Wolf. It was clearly an immense improvement on the old semirigid metal gastroscope, which my predecessor, the late Mr Arthur Edmunds, brought from Germany in 1911, the use of which had been discarded after one or two unfortunate experiences.

The Wolf Schindler gastroscope consisted of a series of convex lenses ensheathed in rubber. It curved in any direction to subtend an angle of some $35^{\circ}$ without distortion of the image, and was claimed to be perfectly safe to pass. It greatly excited my interest.

On inquiry I discovered that the Genitourinary Company had a gastroscope on show, and this through the agency of their $\mathrm{Mr}$ Schranz I was allowed to try. I attempted to use it on just one occasion with the patient under general anaesthesia, but without success. It was clear that failure was due to my lack of expertise and not to the instrument, which obviously had great potential. I was anxious to obtain one and to undergo training in its use in Gernany. But the cost of the instrument was prohibitive- $£ 120$, of which $£ 80$ was the basic cost and $£ 40$ excise duty. In those days this was a considerable sum of money. What its equivalent would buy today is beyond my power to compute. My hospital, like most others, was supported entirely by voluntary contributions, and was permanently in debt. It could provide only the basic needs for surgery. To provide money for an instrument as yet untried in the country was out of the question. It should be remembered also that all senior clinical hospital appointments were strictly honorary. Life was supported entirely by the income from consulting practice; and these were early days in practice for me. The only way open for me to satisfy my ambition seemed to be to go to Germany for a period of training and to buy a gastroscope there, avoiding if possible the excise levy.

But this was a pipe dream-that is, until 1934 when Hitler, who had recently come to power, did the only decent thing he ever did. To lure selected visitors, especially students, to the Reich, reichsmarks were on offer at 22 to the pound sterling instead of the standard rate of 12 , with a limit, so far as I can recall, of $£ 50$. Furthermore, if you had an acceptable project in view, this amount could be doubled. I declared my project, which was accepted. I think the arrangements were negotiated through the German Embassy. This extremely favourable exchange rate would mean that $£ 100$ would easily cover the cost of a week in Germany and a gastroscope-but not the duty. I should have to think out some way of avoiding that.

\section{Off to Germany in 1934}

I was soon on my way to Harwich with 2200 reichsmarks in my pocket-or the equivalent thereof. By this time Dr Schindler, a Jew, had escaped (if that is the right word) to the United States, where he was appointed gastroscopist to a university hospital. His assistant had been Dr Norbut Henning, who was at that time practising in Leipzig, and thither I went. Although we were strangers to each other, Dr Henning gave me a warm welcome. I explained that the

\section{Cambridge}

HAROLD C EDWARDS, MS, FRCS

Correspondence to: 17 Grange Court, Grange Road, Cambridge. purpose of my visit was to learn the technique of gastroscopy. He asked me if I had had any previous experience. I told him about my one abortive attempt under general anaesthesia. There followed a momentary silence of incredulity, and then an outburst of unconstrained laughter from all present. A general anaesthetic for gastroscopy. It was obviously the funniest thing that they had heard for a long time-the joke of the month, if not the year. But they tempered their amusement with kindness, which soon overcame my embarrassment. Thenceforth, they did all that they could to make me feel at home. Dr Henning, whom I had the pleasure of seeing again at meetings after the war, taught me the technique of preparatory local anaesthesia, the technique of introduction of the gastroscope, and the interpretation of what could be seen-even allowing me to pass a gastroscope myself.

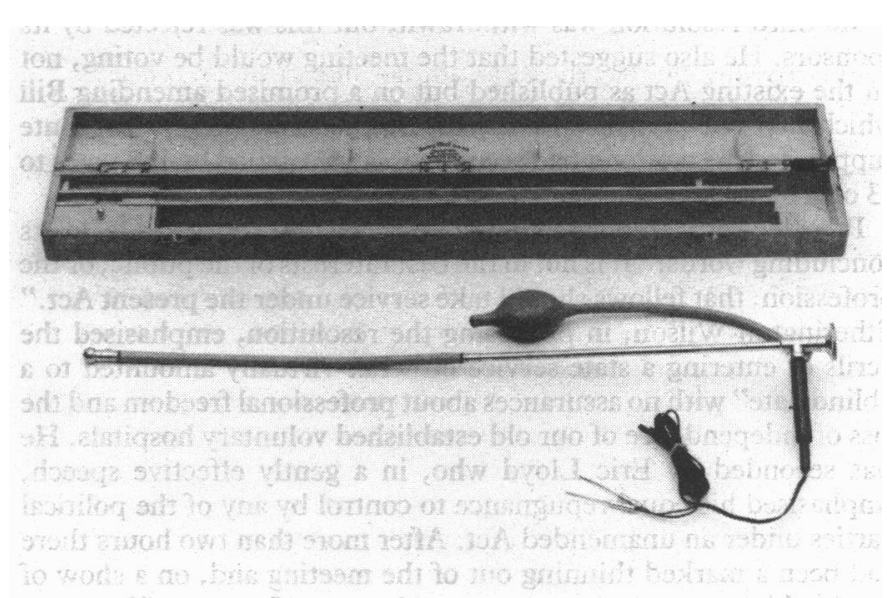

The Wolf gastroscope:

There were some limitations. No control of the distal end was possible once the instrument was passed (such control awaited the ingenious modification devised by $\mathrm{Mr}$ Herman Taylor and $\mathrm{Mr}$ Schranz some years later); and some areas of the stomach-for example, the cardiac end, could not be brought into view. Yet despite these shortcomings I became convinced that the gastroscopy would be an invaluable addition to our diagnostic facilities. To possess one for myself was mandatory.

There was an interesting but somewhat disturbing sidelight to my visit. Dr Henning invited me to a simple meal in his modest flat, where I had the pleasure of meeting Frau Henning. Both were Jewish. The doctor said little, but his wife was very outspoken about the circumstances in which they were obliged to live under the Hitler régime. One of her main complaints was the shortage of books. Dr Henning apologised for not being able to see me on the Sunday. The reason was that every Sunday he had to attend manoeuvres in the field by Hitler's new conscript army, as yet unarmed. The doctor's job was to organise the medical services.

And now from Leipzig to Berlin, where I obtained an appointment to see $\mathrm{Mr}$ Georg Wolf. He received me kindly in his well appointed office. He was a good looking grey haired man with an air of authority. We were soon on common ground. I wanted to buy a gastroscope: he wanted to sell me one. I had calculated that the favourable exchange rate nearly halved the cost- $£ 45$ instead of £80. Mr Wolf's reason for being anxious for a deal was that perhaps I might serve to popularise gastroscopy in the United Kingdom, to his business advantage. I jokingly asked him if I 
could claim any commission. But like a good business man he did not hear or at least not to understand. His knowledge of English seemed to suffer a temporary lapse. And so I bought a gastroscope. It was at this point, with the prospect of paying customs $£ 40$ in sterling, that I resorted to low cunning, the thought of which, now after half a century, begets a sense of guilt. For some time my mind had been occupied with the problem of how to pass through customs financially unscathed. I hit upon the plan of asking $\mathrm{Mr}$ Wolf for a receipt for 20 reichsmarks for "repairs to gastroscope." This he provided without demur. So I left him with my gastroscope and a bogus receipt. The next premeditated act was to buy a toy for my 6 year old son.

That evening I spent much time in my hotel bedroom despoiling the brand new container box with the heel of my shoe, in order to lend it the appearance of age. I then carved my name on the box with a pen knife, inking in the grooves; but such was my state of anxiety that I misspelt my name. I left out the "R," and so the box bore the name of Edwads. The gastroscope is now in the library museum of King's College Hospital medical school, still bearing my distorted name.

\section{Confronting the customs}

My turn to confront customs at Harwich eventually arrived. Few people are at their best at 5 am, especially after a disturbed night crossing the North Sea. I am not one of them. To say I was nervous would be an understatement. My spirits were indeed at the lowest ebb. Down on the counter went my suitcase and my gastroscope. I remember the conversation between myself and the customs officer as though it was yesterday, as one ever remembers experiences under stress.

Customs: "Anything to declare?"
Myself: "Yes, a German toy." (This I extracted from my suitcase and presented to the inquisitor.)

Customs: "That's OK. Anything else?"

Myself: "No, nothing else."

Customs: "What about this?" pointing to the large gastroscope box.

Myself: "Oh that. That is only a surgical instrument."

At this point the young officer became suspicious. He disappeared, to return with a senior colleague with gold rings on his sleeves. He opened the box and examined the gastroscope. I then explained what the instrument was for, and that I was a hospital surgeon returning from a gastroenterological clinic (or did I say conference?) in Leipzig, and that it was part of my essential equipment. "It looks very new," said he. I pointed out that so delicate an instrument had to be maintained in prime condition. He then asked me several searching questions. What was my work? Where did I work? Did I use the instrument regularly? My answers seemed to satisfy him. After some thought, he at last closed the box and, albeit reluctantly, put on the magic white chalk mark. I picked up my belongings with as much nonchalance as I could muster, and made my way to the train. At the barrier I was questioned by a third customs officer, who was interested in the box. But the chalk mark satisfied him. All this delay meant that I nearly missed the train.

I sank into my seat clutching my precious burden. I remember feeling no sense of relief. My adrenals seemed to have stopped working. A minor degree of delayed shock perhaps. But my spirits soon recovered. After all, I had been guilty of no criminal offence; and there had been no need for me to show the bogus receipt from $\mathrm{Mr}$ Wolf. I had obtained a gastroscope for about $£ 45$ plus expenses, which were minimal in view of the favourable rate of exchange that I had been afforded. But I resolved that never again would I tangle with customs.

\title{
Charcot's hysteria renaissant
}

\author{
E M R CRITCHLEY， H E CANTOR
}

\begin{abstract}
The authenticity of Charcot's original descriptions of hysteria has been questioned in the popular media. None the less, it is still possible to encounter florid forms of hysteria in culturally deprived communities, and to answer Charcot's present day critics we present a selection of patients from Kentucky's Appalachian counties with hysterial neurological disease. Their case histories are contrasted with those Charcot himself described and thereby form a modern commentary on such conditions as la grande hystérie, hysteroepilepsy, hysterotraumatic monoplegia, and hysterical hemianaesthesia.
\end{abstract}

\section{Introduction}

Hysteria is present when there is a disproportionate relation of symptoms to disability and a discrepancy between the manifestations and the anatomical and physiological arrangements of the body. ${ }^{1}$ Caution must be exercised in accepting even the most florid presentations, and hysteria presenting with neurological symptoms may be especially misleading. ${ }^{2}$ Furthermore, the physician has the added duty to understand why the patient has taken to express himself or herself subconsciously in this manner. The unexpectedly high incidence of hysterical disorders among the underprivileged white community of Kentucky's Appalachian counties is a matter of surprise, matched only by the similarities of these disorders to the original descriptions of Charcot in his clinical lectures on diseases of the nervous system. ${ }^{3}$

\section{Clinical presentations}

One of the most startling forms of hysteria that Charcot demonstrated at the Salpêtrière was la grande hystérie, otherwise called hysteria major or hysteroepilepsy with distinctive crises. Freud described la grande hystérie as consisting of four phases ${ }^{4}$ : the epileptoid; violent movements; attitudes passionnelles (the hallucinatory phase); and the concluding delirium. According to 